\title{
Long-term observations on the mortality of mentally ill patients admitted to a short- stay psychiatric hospital: 23 years retrospective Egyptian study
}

Dalia H. Ali ${ }^{*}$ D, Eman Shorab, Ghada A.M. Hassan, Amany Haroun elRasheed, Marwa Abdel Rhman Soltan and Hanan Elrassas

\begin{abstract}
Background: Information about mortality patterns in different psychiatric populations is scanty, yet it is vital for designing successful preventive mental health strategies. In this study, we aimed to assess mortality rates and patterns for the patients admitted to Ain Shams University Institute of Psychiatry (ASUIP) with different psychiatric diagnoses from1990 to 2013. All medical records and related registration files were reviewed and investigated for death cases and their possible causes in a retrospective record linkage study. Data were recorded, tabulated, and coded to be used in the Statistical Package for Social Sciences (SPSS) Version 17.

Results: The study identified 57 death cases in 23 -years duration with a mortality rate of $3 / 1000$. Mortality rates were more in younger patients and females. Medical comorbidity was reported in $34.8 \%$ of them. The most common known causes for death in the current sample were cardiac causes $15.2 \%$, followed by cerebrovascular causes that were $10.9 \%$. However, sudden or unknown causes were the most frequent diagnosis in the sample.

Conclusions: The institute mortality rates were lower than those of the general population during this period. The most common known death causes were cardiovascular problems, which mandates close monitoring of high-risk psychiatric patients with co-morbid cardiac problems. Unknown morality causes represented an unresolved challenge for the current registration system and the quality of care given to patients with serious mental illness.
\end{abstract}

Keywords: Mortality rates, Death causes, Serious mental illness

\section{Background}

Patients suffering from common mental disorders, especially persons with psychotic disorders, major depressive disorders, and substance use disorders, are at high risk of premature death $[1,2]$. This risk is not similar for all mental health problems, and the underlying causes of death may also vary $[1,2]$. Mortality can be as high as two

*Correspondence: daliahegazy74@yahoo.com

Institute of Psychiatry, Faculty of Medicine, Ain Shams University, Cairo, Egypt or three times that in the general population in patients of some serious mental disorders (SMD) [3, 4].

Mental and behavioral disorders account for 8.6 million $(0.5 \%)$ of all years of life lost to premature mortality [5]. Some high-quality studies from Ethiopia and Bali reported that the average potential years of life lost for persons with SMD was 28.4 years [6,7].

Sixty percent of patients with serious mental illness (SMI) mortalities are due to physical illnesses that are also prevalent in the general population. Yet, the fact that the access to high-quality health care services is difficult 
for those population negatively impacted their medical outcome $[8,9]$.

In Egypt, there is a lack of published data on the state of health, morbidity, and mortality of people with serious mental illness, both on the community and the mental health hospital level. This retrospective record linkage study aimed to assess mortality rate, medical comorbidities, and death causes when possible for the patients admitted to the Institute of Psychiatry, Ain Shams University, from its opening 1990, till the end of 2013.

\section{Methods}

\section{Study cohort}

All data were collected retrospectively from Ain Shams University Institute of Psychiatry (ASUIP) files. The institute is a WHO collaborative center for research and training that provides 3 years of a residency program in neuropsychiatry and training program for a master and doctorate degree in psychiatry. It is a short-stay psychiatric hospital, where admitted patients stay between 1 and 2 months. It contains 105 beds for inpatient admission services in addition to outpatient clinics that cover all psychiatric domains 4 days a week (about 80 patients/ day).

The institute is located in eastern Cairo and serves both urban and rural areas, middle, and low social class population. It is in the catchment area for more than 20 million inhabitants.

Research Ethics Committee of the faculty of medicine at Ain Shams University approved the study proposal. A well-trained team on data collection and data categorization reviewed ASUIP inpatient registration system database and medical records in October 2013 and for 3 months. From 17,562 files (4395 females and 13167males) of adult inpatient admissions for serious mental health conditions, between 1990 and 2013, mortality reports saved in Ain Shams University Hospital's health care system and ASUIP registration system identified 57 death events for the same period. Needed data analysis was completed for 46 death event files. Eleven files were discarded and excluded from the study due to missing data.

\section{Procedure}

\section{Collected data were subjected to the following}

All information in the patients' files, including mortality reports, were reviewed and examined manually and categorized by a trained team member. The data included patients' socio-demographic characteristics and admission psychiatric diagnoses, according to ICD-10, categorized in the main groups. Schizophrenia, schizoaffective, delusional, and other non-organic psychotic disorders, and acute psychotic episodes were grouped under psychotic disorders. We collected data about patients; last admission in days, co-morbid medical conditions and lab investigations results, psychotropic medications given in the incident-related episode and its doses, ECT (electroconvulsive therapy) regimen if was given and any reported complications, investigation and interventions before death together with features of the incident, and the number of consultations to other specialties before the death incident, consultations done, plan of management followed at that time (as transfer to a general medical hospital, emergency, or conservative management).

\section{Information about mortality causes for cases was coded and divided into five main categories}

- Unknown and sudden causes: for those who died without reporting any new medical complications in the last week before death or died before proper medical examination and investigation of the case.

- Cardiac causes: for cases of cardiovascular complications, i.e., heart failure or myocardial infarction prior to the death event.

- Neurological causes: in cases of cerebrovascular stroke, delirium, or encephalitis.

- Other medical causes: This group included cases with respiratory failure, renal failure, concurrent infection, and metabolic causes.

Mortality rates over the 23 years were calculated and recorded. The general mortality rate in Egypt at the same period was also recorded for analytical reasons.

\section{Statistical analysis}

All the data was recorded, tabulated, and transferred on Statistical Package for Social Sciences (SPSS) Version 17. For descriptive data, we used means and standard deviation (SD). Quantitative data were analyzed using a $t$ test. Pearson's chi-square and cross-stab for analysis and relation of categorical variables $\left(X^{2}\right) . P$ value $<0.05$ was used to indicate the level of significance.

\section{Results}

\section{Characteristics of the study population}

In 23 years, 17,562 patients were admitted, 13,167 male patients, and 4395 females. Fifty-seven patients died during this period, 46 of them had complete files, and 11patients had incomplete records.

The calculated total mortality rate in the study period was $3 / 1000$. The mortality rate in females was significantly higher than males 6/1000 (26/4395) and 2/1000 (20/13167), respectively. This significant difference was not evident in other clinical variables as age, comorbidity, vital data, and medication, $P$ value $<0.05$ (Table 1 and 2 ). 
Table 1 Sample socio-demographic and clinical characteristics

\begin{tabular}{|c|c|c|}
\hline The study sample & & $N=46$ \\
\hline \multirow[t]{2}{*}{ Age in years } & $\mathrm{M} \pm \mathrm{SD}$ & $42.2 \pm 14.7$ \\
\hline & Range & $20-81$ \\
\hline \multirow[t]{2}{*}{ Age per gender } & Male & $41.4 \pm 14.5$ \\
\hline & Female & $42.8 \pm 15.1$ \\
\hline \multirow[t]{2}{*}{ Reported deaths in 23 years } & Males & $20(43.5 \%)$ \\
\hline & Females & $26(56.5 \%)$ \\
\hline \multirow[t]{2}{*}{ Number of admission in 23 years } & Males & 13,167 \\
\hline & Females & 4395 \\
\hline \multirow[t]{2}{*}{ Duration of hospitalization in days } & $\mathrm{M} \pm \mathrm{SD}$ & $11.5 \pm 14.7$ \\
\hline & Range & 1-90 days \\
\hline Die in the first week & & $28(60.8 \%)$ \\
\hline
\end{tabular}

Table 2 Sample diagnostic categories and medical comorbidities

\begin{tabular}{|c|c|c|}
\hline Diagnosis & & Total $=46$ \\
\hline Dementia & & $2(4.3 \%)$ \\
\hline Substance use disorder & & $1(2.2 \%)$ \\
\hline Psychotic & & $14(30.4 \%)$ \\
\hline Bipolar affective disorder (Manic) & & $9(19.6 \%)$ \\
\hline Major depression & & $15(32.6 \%)$ \\
\hline Catatonia & & $3(6.5 \%)$ \\
\hline Aggression for investigations & & $2(4.3 \%)$ \\
\hline \multirow[t]{3}{*}{ Medical co-morbidity } & No co-morbidity & $26(56.5 \%)$ \\
\hline & One co-morbidity & $16(34.8 \%)$ \\
\hline & Multiple co-morbidities & $4(8.7 \%)$ \\
\hline
\end{tabular}

In the studied sample, the most common psychiatric diagnosis was depression which is 15 (32.6\%) patients followed by the psychotic disorder group (schizophrenia and schizoaffective, delusional disorders) which is 14 (30.4\%) patients. More than half of the sample has no history of medical comorbidity 26 (56.5\%) (Table 2).

The total number of deaths in 23years (study duration) was 57. Data of 46 deaths are represented in Table 2. As observed, 20 (43.5\%) patients received typical antipsychotic, while 4 (8.7\%) received atypical antipsychotics (APD). Four (8.7\%) patients received antidepressant medications. Moreover, 24 (52.2\%) patients received polypharmacy versus 19 (41.3\%) received monotherapy, and $3(6.5 \%)$ patients stopped treatment for medical reasons (Table 3).

\section{Medical complications and lab results recorded before the death event}

Patients' medical records showed that patients were submitted to medical examination and routine investigations on admission, including $\mathrm{CBC}$, liver, renal function, and
RBS. $19.6 \%$ of the sample showed abnormal lab results in more than one domain.

Disturbed vital data (blood pressure and heart rate) and fever were the most frequently reported complications 34 (73.9\%) and 21 (45.7\%), respectively. No reported complications prior to death in $19.6 \%$ of the sample. $86.8 \%$ of the sample did not report drug complications.

Medical consultation and interventions 1 week before the death incident were reported in 19 (41.3\%) patients. Conservative management procedures were evident in 9 (19.6\%) of patients, while transfer to specialized medical department and ICU was reported in $10(21.7 \%)$ patients. Twenty-one (45.7\%) patients received ECT and 2 (4.4\%) of them reported complications as shown in Table 4.

\section{Correlation study data \\ Death cause in relation to patients' mean age}

Younger mean ages were noted in the sudden unexplained death (SUD) group with a mean of $39.1 \pm 11$. Older mean ages were noted in the cardiac cause group with a mean of $47.8 \pm 9.6$, as shown in Table 5 .

\section{Polypharmacy and cause of death}

Comparing different causes of death in relation to the type of drug revealed no significant difference as $P$ was 0.502 . Similarly comparing different causes of death in relation to pharmacotherapy (monotherapy versus polypharmacy) revealed no significant difference of 0.066 (Table 6).

\section{Discussion}

Historical data have always been focusing on over-estimating the rate of unnatural deaths in inpatient populations with SMD (suicide, accidents, and homicides). It is known that the mortality gap cannot be attributed to this alone [10]. The linked data from mental and physical health services reported that the excess deaths were attributable to physical illnesses in over three-quarters of cases [10]. More attentive checks for psychiatric patient's physical illness, side effects of medications, and suicidal tendencies can take mortality rates to lower limits.

In this study, retrospective data analysis for 17,562 patient files, admitted to ASUIP during this period, revealed a mortality rate of $0.32 \% .56 .5 \%$ of the reported death cases were female patients. The general mortality rate in Egypt in the same period between 1990 and 2013 was 6.2 to 6.9 per 1000 population [11]. In other words, in this study mortality rate was nearly half the national reported average by the National Center for Health Statistics (NCHS) Public Health Surveillance, Population demographic reports 2015 [12].

Hewer and his colleagues reported higher inpatient mortality rates (1.38\%) in German psychiatric hospitals 
Table 3 Types of drugs, number of deaths, and admissions/year

\begin{tabular}{|c|c|c|c|c|c|c|c|}
\hline & \multirow{2}{*}{$\begin{array}{l}\text { Number of } \\
\text { admission }\end{array}$} & \multirow[t]{2}{*}{ Deaths } & \multicolumn{5}{|c|}{ Type of drug } \\
\hline & & & Typical & Atypical & ADD & Polypharmacy & $\begin{array}{l}\text { No } \\
\text { treatment }\end{array}$ \\
\hline 1990 & 193 & 2 & 2 & 0 & 0 & 1 & 0 \\
\hline 1991 & 731 & 3 & 0 & 0 & 0 & 1 & 2 \\
\hline 1993 & 605 & 1 & 1 & 0 & 0 & 0 & 0 \\
\hline 1994 & 705 & 5 & 2 & 0 & 0 & 3 & 0 \\
\hline 95 & 872 & 7 & 4 & 0 & 1 & 3 & 0 \\
\hline 96 & 716 & 2 & 2 & 0 & 0 & 2 & 0 \\
\hline 98 & 748 & 4 & 4 & 0 & 0 & 1 & 0 \\
\hline 99 & 733 & 9 & 2 & 0 & 0 & 1 & 1 \\
\hline 2000 & 670 & 2 & 2 & 0 & 0 & 2 & 0 \\
\hline 2001 & 727 & 1 & - & - & - & - & - \\
\hline 2002 & 688 & 7 & 1 & 2 & 0 & 5 & 0 \\
\hline 2003 & 747 & 2 & 0 & 1 & 0 & 1 & 0 \\
\hline 2004 & 861 & 1 & - & - & - & - & - \\
\hline 2005 & 8985 & 3 & - & - & - & - & - \\
\hline 2006 & 840 & 1 & - & - & - & - & - \\
\hline 2007 & 974 & 1 & 0 & 0 & 1 & 1 & 0 \\
\hline 2008 & 668 & 2 & 0 & 1 & 1 & 1 & 0 \\
\hline 2009 & 691 & 1 & - & - & - & - & - \\
\hline 2010 & 615 & 1 & 0 & 0 & 0 & 1 & 0 \\
\hline 2012 & 861 & 1 & 0 & 0 & 1 & 0 & 0 \\
\hline 2013 & 636 & 1 & 0 & 0 & 0 & 1 & 0 \\
\hline $\begin{array}{l}\text { Total Number of } \\
\text { admission }\end{array}$ & 17562 & 57 & 20 & 4 & 4 & 24 & 3 \\
\hline
\end{tabular}

NB missing data for 11 deaths, exclude years with zero mortality

[13]. Khamker and his colleagues reported near figure (1.47\%) in a South African psychiatric hospital [14]. Although persons with SMD are dying younger than the general population globally, there is an emerging consensus that the majority of excess mortality is due to poor physical health, with cardiovascular disease as the primary cause of death [15].

Applying high standards and best practice guidelines in assessment and monitoring patients' physical and mental conditions as in the case of ASUIP, in addition to the restricting admission criteria excluding organic mental disorders unless well investigated and controlled, kept inpatients mortality rates to lower limits.

Rare studies were directed toward the analysis of mortality rates differences between long and short-stay mental health hospitals, but considering that ASUIP is a short-stay hospital, excluded other involved mortality causes related to long hospital admissions.

In agreement with other studies showed higher death rates in younger patients $(42.2 \pm 14.7)$ years [16-18]. Nevertheless, it came to the contrary to other studies that reported higher mortality in older age groups 50 and 70 years, respectively $[14,13]$. This variation could be attributed to the younger age of admission in ASUIP versus older age ranges of patients, with organic mental diseases in other studied settings. This age range was much younger than the mean age of death in general population as general mortality rate in Egypt in 2013 was 70.8 years [19].

In this study, the number of admitted female patients in ASUIP was less than half the number of admitted males during the same period. Despite the data showed no statistically significant differences in both sexes in clinical variables, female patients had a higher mortality rate $6 / 1000$ versus $2 / 1000$ in males. Similarly, other studies reported slightly higher female mortality rates [13, $17,20]$. However, other studies failed to find differences among females and males [16] or even found a reversed male-female ratio with more reported male mortality [14].

The mean duration of hospitalization in ASUIP was $11.5 \pm 14.7$ days, with a range of $1-90$ days. In contrast, previous studies reported that a more extended admission period was associated with inpatient death 
Table 4 Dead cases reported complications and lab results during the admission period

\begin{tabular}{|c|c|c|}
\hline \multicolumn{2}{|l|}{ Type of complication } & \multirow{2}{*}{$\begin{array}{l}\text { Frequency (\%) } \\
9(19.6 \%)\end{array}$} \\
\hline No complications & & \\
\hline Cardiac complications & & $13(28.3 \%)$ \\
\hline \multirow[t]{2}{*}{ Neurological complications } & CVS & $6(13 \%)$ \\
\hline & Delirium & $17(37 \%)$ \\
\hline \multicolumn{2}{|c|}{ Disturbed vital data (blood pressure and heart rate) } & $34(73.9 \%)$ \\
\hline \multicolumn{2}{|c|}{ Fever } & $21(45.7 \%)$ \\
\hline \multicolumn{2}{|l|}{ Infection } & $10(21.7 \%)$ \\
\hline \multicolumn{2}{|l|}{ Complications due to ECT } & $2(4.4 \%)$ \\
\hline \multicolumn{2}{|l|}{ More than one complication } & $10(21.7 \%)$ \\
\hline \multirow[t]{6}{*}{ Complication of drugs } & No & $40(86.8 \%)$ \\
\hline & NMS & $1(2.2 \%)$ \\
\hline & Delirium & $1(2.2 \%)$ \\
\hline & Cardiac & $2(4.4 \%)$ \\
\hline & Agranulocytosis & $1(2.2 \%)$ \\
\hline & Constipation & $1(2.2 \%)$ \\
\hline Lab results & Frequency (\%) & \\
\hline No abnormalities in lab & $21(45.7 \%)$ & \\
\hline Impaired renal function & $4(8.7 \%)$ & \\
\hline Impaired liver function & $1(2.2 \%)$ & \\
\hline Impaired FBS & $2(4.3 \%)$ & \\
\hline High ESR & $1(2.2 \%)$ & \\
\hline Electrolyte disturbances & $3(6.5 \%)$ & \\
\hline More than one abnormalities & $9(19.6 \%)$ & \\
\hline Agranulocytosis & $1(2.2 \%)$ & \\
\hline Low hemoglobin level & $4(8.6 \%)$ & \\
\hline
\end{tabular}

CVS cerebrovascular stroke, FBS fasting blood sugar, ESR erythrocyte sedimentation rate, NMS neuromalignant syndrome

Table 5 Study sample death causes and mean age

\begin{tabular}{lll}
\hline Cause of death & & $\boldsymbol{N}=\mathbf{4 6}$ \\
\hline SUD or unknown & $\boldsymbol{N}$ & $19(41.3 \%)$ \\
& Mean age(M+/-SD) & $39.1 \pm 11$ \\
Neurological (CVS) & $\boldsymbol{N}$ & $5(10.9 \%)$ \\
& $\boldsymbol{M e a n}$ age $(\mathbf{M} \pm$ SD) & $41.7 \pm 18.3$ \\
Cardiac & $\boldsymbol{N}$ & $7(15.2 \%)$ \\
& Mean age $(\mathbf{M} \pm$ SD) & $47.8 \pm 9.6$ \\
Other medical & $\boldsymbol{N}$ & $15(32.6 \%)$ \\
& Mean age $(\mathbf{M} \pm$ SD) & $40 \pm 9.6$ \\
\hline
\end{tabular}

SUD sudden unexplained death, CVS cerebro-vascular stroke, other medical renal failure, respiratory, bleeding, metabolic, and septicemia

incidence. However, it is worth mentioning that Khamker and colleague's study reported that $25 \%$ of the death incidence occurred in the first month of admission [14].

Major depression (32.6\%) followed by schizophrenia (30.4\%) were the most frequent diagnoses with reported mortality, while substance use disorder was
Table 6 Causes of death and type of pharmacotherapy among the sample

\begin{tabular}{|c|c|c|c|c|}
\hline \multicolumn{2}{|c|}{ Type of pharmacotherapy } & Polypharmacy & Monotherapy & Total \\
\hline \multicolumn{2}{|l|}{ SUD or unknown } & 7 & 12 & 19 \\
\hline \multicolumn{2}{|l|}{ Neurological (CVS) } & 5 & 0 & 5 \\
\hline \multicolumn{2}{|l|}{ Cardiac } & 4 & 2 & 6 \\
\hline \multicolumn{2}{|l|}{ Other } & 8 & 5 & 13 \\
\hline \multicolumn{2}{|l|}{ Total } & 24 & 19 & 43 \\
\hline \multirow[t]{2}{*}{ Sig } & Df & 3 & & \\
\hline & Sig & 0.066 & & \\
\hline
\end{tabular}

Other (renal, respiratory, bleeding, metabolic, septicemia, overdose)

least frequent in the current study. Similar findings were detected in West Africa institute, in their cohort, schizophrenia (26\%), and major depression (25\%) constituted the main psychiatric diagnoses at the time of admission [17]. Hewer and his colleagues found that organic mental disorder had a high mortality risk [13].

Natural causes were the primary etiology of death among psychiatric patients, and their rates differ in different studies [14]. Consistently, in this study, natural death causes were responsible for all cases with a known and unknown causes. Cardiac complications were implicated in most of the death reports, followed by cerebrovascular accidents. Other death causes, which include renal failure, respiratory complications, bleeding, metabolic problems, septicemia, and drug intoxication, were involved in more than a quarter of the morality. Cases of patients who died without reporting any new medical complications in the last week before death or died before proper medical examination and investigation were counted as a separate group not under cardiac death causes group, despite that the registered cause of death in their death report was a sudden circulatory system failure. Sudden or unknown causes of death were reported in $41.3 \%$ of the sample. The high rate of disturbed vital data reported in the current study may raise the question about cardiac causes as a possible hidden cause of death in those cases $[21,22]$.

Cardiovascular causes were the most reported natural cause of death in psychiatric inpatients in previous different studies [16, 23]. Increased risk of cardiovascular diseases in psychiatric patients could be explained as a result of the use of antipsychotic drugs, psychosocial deprivation, and sedentary lifestyle as excessive smoking and physical inactivity $[14,21,22]$. Furthermore, cardiovascular causes could be the leading cause of sudden unknown deaths of psychiatric patients [24]. Interestingly, the main known causes of mortality in psychiatric inpatients differ in different populations. 
Different death causes can explain part of that in a particular general population, as in the case of inconvenient socioeconomic factors and level of medical care in some communities and prevalence of infections or other endemic diseases in others. Infections were the most common natural cause of death in Singapore, South, and West Africa studies [14, 17, 20].

Remarkably, unnatural causes of mortality, such as suicide and injuries, were not reported in the current study. In contrast, suicide was the main unnatural cause reported by other studies [16]. Factors as the close follow-up of patients, short-stay hospitalization, proper medical care, and use of ECT could explain this finding.

The present study had some limitations, including incomplete files during registration, difficulty to access, and the improper documentation of some critical clinical data in patients' medical records, a high percentage of unknown death causes. The absence of essential comparative statistics data in this study was due to the lack of information about mortality patterns in patients with mental illness in the Egyptian community and in the Arab countries. This limitation should direct mental health planners and other stakeholders' efforts toward extensive epidemiological research projects, and the adoption of more functional registration systems. In addition to applying best practice guidelines in providing medical and mental health services to this population.

\section{Conclusions}

This study detected lower mortality rates compared to the general population. The most common known causes involved in patients mortality were cardiovascular diseases. Thus, close monitoring for psychiatric inpatients at high risk of cardiovascular complications is warranted. Interestingly also, this study highlighted patients with severe mental disorder needs for a more accessible and comprehensive, community-based, prevention, identification, and intervention medical care programs that address their physical and mental health [25].

\section{Abbreviations}

ASUIP: Ain Shams University Institute of Psychiatry; SUD: Sudden unexplained death; CVS: Cerebro-vascular stroke; ECT: Electroconvulsive therapy; FBS: Fasting blood sugar; ESR: Erythrocyte sedimentation rate; NMS: Neuro-malignant syndrome.

\section{Acknowledgements}

None.

\section{Authors' contributions}

$\mathrm{HE}, \mathrm{DH}$, and $\mathrm{ESH}$ analyzed the data and interpreted it. $\mathrm{GH}, \mathrm{AH}$, and MS suggested the topic and shared in the methodology and interpretation. $\mathrm{DH}$ and $\mathrm{HE}$ searched for the resources and were the main contributors in writing the manuscript. The authors read and approved the final manuscript for submission.
Funding

None.

Availability of data and materials

Not applicable.

\section{Declarations}

Ethics approval and consent for participate

The study protocol was approved by the Ethics and Research Committee of the Institute of Psychiatry, Faculty of Medicine, Ain Shams University. The committee's reference number is not available. Patients' written consents for participation were included in the patient files as a routine procedure of their admission process in the institute. Patients approve that their data can be used later for scientific purposes.

\section{Consent for publication}

Not applicable.

\section{Competing interests}

The authors declare that they have no competing interests.

Received: 3 October 2021 Accepted: 19 October 2021

Published online: 22 December 2021

\section{References}

1. Björkenstam E, Ljung R, Burström B, Mittendorfer-Rutz E, Hallqvist J, Weitoft GR (2012) Quality of medical care and excess mortality in psychiatric patients: a nationwide register-based study in Sweden. BMJ Open 2:e000778. https://doi.org/10.1136/bmjopen-2011-000778.

2. Ajetunmobi O, Taylor M, Stockton D, Wood R (2013) Early death in those previously hospitalized for mental healthcare in Scotland: a nationwide cohort study, 1986-2010. BMJ Open 3(7) [PMC free article][PubMed] [Google Scholar]

3. Harris EC, Barraclough B (1998) Excess mortality of mental disorder. Br J Psychiatry 173:11-53. https://doi.org/10.1192/bjp.173.1.11

4. Ran E, Rouillon F, Loze JY, Casadebaig F, Philippe A, Vitry F et al (2009) Cancer mortality in patients with schizophrenia: an 11-year prospective cohort study. Cancer 115:3555-3562 [PubMed]

5. Whiteford HA, Degenhardt L, Rehm J et al (2013) Global burden of disease attributable to mental and substance use disorders: findings from the Global Burden of Disease Study. Lancet 382(9904):1575-1586. https:// doi.org/10.1016/S0140-6736(13)61611-6 Epub 2013 Aug 29. Review. PMID:23993280

6. Fekadu A, Medhin G, Kebede D, Alem A, Cleare AJ, Prince M et al (2015) Excess mortality in severe mental illness: 10-year population-based cohort study in rural Ethiopia. Br J Psychiatry 206:289-296. https://doi. org/10.1192/bjp.bp.114.149112 [PubMed] [CrossRef] [Google Scholar]

7. Kurihara T, Kato M, Reverger R, Tirta IGR (2011) Seventeen-year clinical outcome of schizophrenia in Bali. EurPsychiatry 26:333. https://doi.org/10. 1016/j.eurpsy.2011.04.003 [PubMed] [CrossRef] [Google Scholar]

8. Vreeland B (2007) Bridging the gap between mental and physical health: a multi-disciplinary approach. J Clin Psychiatry 68(4):26-33

9. Barbara M 2006. Morbidity and mortality in people with serious mental illness edited by Joe Parks, MD Dale Svendsen, MD Patricia Singer, MD Mary Ellen Foti. National Association of State Mental Health Program Directors (NASMHPD) Medical Directors Council 66 Canal Center Plaza, Suite 302, Alexandria VA 22314 703-739-9333 FAX: 703-548-9517 www. nasmhpd.org.

10. Lawrence D, Hancock KJ, Kisely S (2013) The gap in life expectancy from preventable physical illness in psychiatric patients in Western Australia: retrospective analysis of population based registers. BMJ 346. https://doi. org/10.1136/bmj.f2539 [PMC free article] [PubMed] [CrossRef] [Google Scholar]

11. WHO-EM/HST/225/E 1(2015). Health status - Egypt: World Health Organization. Regional Office for the Eastern Mediterranean Egypt health profile/World Health Organization. 
12. El-Zanaty F, Way A (2009) Egypt demographic and health survey 2008. Ministry of Health and Population, El-Zanaty and Associates and Macro International, Cairo (http://dhsprogram.com/pubs/pdf/fr220/fr220.pdf, Accessed 6 Jul 2015)

13. Hewer W, Rossler W, Fatkenheuer B et al (1995) Mortality among patients in psychiatric hospitals in Germany. Acta Psychiatr Scand 91:174-179

14. Khamker N, Moola NM, Roos JL et al (2010) Profile of mortality of patients admitted to Weskoppies Psychiatric Hospital in South Africa over a 5-year period (2001-2005). Afr J Psychiatry (Johannesbg) 13:211-217

15. Barber S, Thornicroft G (2018) Reducing the mortality gap in people with severe mental disorders 2018: the role of lifestyle psychosocial interventions. Front Psych 9:463. https://doi.org/10.3389/fpsyt.2018.00463 Published online 2018 Sep 28. PMCID: PMC6172296, PMID: 30323773

16. Valenti M, Necozione S, Busellu G et al (1997) Mortality in psychiatric hospital patients: a cohort analysis of prognostic factors. Int J Epidemiol 26:1227-1235. https://doi.org/10.1093/ije/26.6.1227

17. Malomo IO, Aina OF, Ladapo HT et al (2003) Ten-year mortality review in a pioneer psychiatric hospital in West Africa. East Afr Med J 80:379-383. https://doi.org/10.4314/eamj.v80i7.8723

18. Fiorittia A, Lipparinia D, Melegaa V (1994) Mortality of long-term psychiatric inpatients: retrospective study on a cohort of long-term patients in the psychiatric hospital of Bologna, Italy. Epidemiol Psichiatr Soc 3:107-114. https://doi.org/10.1017/S1121189X00003559

19. Reports of the National Center for Health Statistics 2015 (NCHS).Hyattsville (MD): National Center for Health Statistics (US); 2016 May. Report No.: 2016-1232. Health, United States.
20. Lim LC, Sim LP, Chiam PC (1991) Mortality among psychiatric inpatients in Singapore. Singapore Med J32:130-132

21. Jones DR, Macias C, Barreira PJ et al (2004) Prevalence, severity, and cooccurrence of chronic physical health problems of persons with serious mental illness. Psychiatr Serv 55:1250-1257. https://doi.org/10.1176/appi. ps.55.11.1250

22. Kilbourne AM, Morden NE, Austin Ket al (2009) Excess heart-diseaserelated mortality in a national study of patients with mental disorders: identifying modifiable risk factors. Gen Hosp Psychiatry 31:555-563. https://doi.org/10.1016/j.genhosppsych.2009.07.008

23. Casadebaig F, Quemada N (1989) Mortality in psychiatric inpatients. Acta Psychiatr Scand 79:257-264

24. Appleby L, Thomas S, Ferrier N et al (2000) Sudden unexplained death in psychiatric in-patients. Br J Psychiatry 176:405-406. https://doi.org/10. 1192/bjp.176.5.405 Published online by Cambridge University Press: 02 January 2018

25. Information sheet premature death among people with severe mental disorders. WHO; 2015. https://apps.who.int/iris/handle/10665/112738.

\section{Publisher's Note}

Springer Nature remains neutral with regard to jurisdictional claims in published maps and institutional affiliations.

\section{Submit your manuscript to a SpringerOpen ${ }^{\circ}$ journal and benefit from:}

- Convenient online submission

$\checkmark$ Rigorous peer review

- Open access: articles freely available online

- High visibility within the field

- Retaining the copyright to your article

Submit your next manuscript at $\boldsymbol{\nabla}$ springeropen.com 